4. Сгонник Л. В. Проектная деятельность в развитии личностных и профессиональных качеств студентов педагогического вуза // Молодой ученый. - 2016. - № 5 (109). - С. 1-4.

5. Тамбовцева Р. А. Методические рекомендации по подготовке и проведению мастер-классов и открытых занятий в системе дополнительного образования [Электронный ресурс]. - URL: https://www.prodlenka.org/metodicheskie-razrabotki/97737-metodicheskie-rekomendacii-popodgotovke-i-pr (дата обращения: 01.04.21).

6. Урок НТИ [Электронный ресурс]. - URL: https://nti-lesson.ru (дата обращения: 20.03.21).

\title{
Надеждин Е.Н. \\ О роли учебной мотивации в обеспечении качества вузовской подготовки будущих ИТ-специалистов
}

ФГБОУ ВО «Российский государственный гуманитарный университет»

(Россия, Москва)

doi: $10.18411 / \mathrm{lj}-05-2021-243$

\section{Аннотация}

Данная статья посвящена анализу структуры и роли учебной мотивации в освоении основной образовательной программы бакалавриата по направлению подготовки 02.03.02 «Фундаментальная информатика и информационные технологии». Рассматриваются основные теоретические и прикладные аспекты проблемы мотивации и особенности её формирования у студентов в период научно-исследовательской практики. Для поддержки мотивации студентов к обучению предложен комплексный подход к целенаправленному формиро-ванию ключевых групповых и личностных мотивов на основе осуществления предложенной концепции активной проектной деятельности.

Ключевые слова: учебная мотивация, научно-исследовательская практика студентов, проектная деятельность, комплексный подход, концепция активной проектной деятельности.

\section{Abstract}

This article is devoted to the analysis of the structure and role of educational motivation in the development of the main educational program of the bachelor's degree in the direction of training 02.03.02 "Fundamental Informatics and information technologies". The main theoretical and applied aspects of the problem of motivation and the features of its formation in students during the period of research practice are considered. To support the motivation of students to study, a comprehensive approach to the purposeful formation of key group and personal motives based on the implementation of the proposed concept of active project activity is proposed.

Keywords: educational motivation, research practice of students, project activity, integrated approach, the concept of active project activity.

Для ликвидации технологического отставания и создания платформы для последующего научно-технического прорыва в ведущих отраслях промышленного производства, России требуются квалифицированные инженерные кадры, обладающие необходимыми профессиональными знаниями, умениями и навыками. При этом в решении актуальных проблем цифровой экономики ведущая роль отводится специалистам в сфере информационных и коммуникационных технологий. В этой связи на современном этапе социально-экономического развития взят и успешно реализуется курс на глубокое реформирование системы высшего образования в контексте новой образовательной парадигмы. 
Цель статьи - анализ места и роли учебной мотивации в системе подготовки будущих бакалавров по направлению 02.03 .02 «Фундаментальная информатика и информационные технологии» (профиль «Открытые информа-ционные системы).

Исследованию проблемы формирования учебной мотивации в общем, специальном и высшем образовании посвящено большое количество трудов отечественных и зарубежных ученых. Однако, общий методический подход к проблеме усиления учебной мотивации обучающейся молодёжи до настоящего времени не сформирован. В значительной степени это связано с нестабильностью политической обстановки в мире, с непрерывным изменением социально-экономических условий, вариативностью задач и условий обучения, а также с уникальностью личности обучающегося.

В классических психолого-педагогических работах учебная мотивация понимается как совокупность побуждающих факторов, определяющих активность личности и направленность её учебной деятельности [1, с.6]. К числу таких факторов следует отнести: мотивы, потребности, стимулы, ситуативные факторы, которые детерминируют поведение человека.

Последние психолого-педагогические исследования, выполненные извест-ными учёными-психологами [2, 3], позволили охарактеризовать мотивацию как относительно устойчивое системное образование, обеспечивающее побуждение, направленность и регуляцию выполнения деятельности. По утверждению Т.О. Гордеевой мотивация может быть интерпретирована как сложная динамическая система, которая включает «иерархию внутренних и внешних мотивов, постановку целей $и$ планирование конкретных действий, направленных на реализацию этих иелей, упорство и настойчивость, стратегии реагирования на трудности и неудачи, возникающие при выполнении деятельности, а также разнообразные когнитивно-мотивационные составляюшие» [4].

Продолжая обозначенную линию исследования, учебную мотивацию можно представить в виде многоуровневой семантической модели, в которой концептами выступают мотивы, побуждающие обучающегося к активной интеллектуальной деятельности.

На рисунке 1 показаны основные структурные компоненты (мотивы) модели учебной мотивации [3]. В настоящее время выявить и количественно оценить структурные связи между мотивами, а также отобразить их графически достаточно сложно в силу их неоднозначности, нестационарности и недостаточной изученности. Дополнительно отметим, что на этапе глобализации технологических и информационных процессов и одновременного усиления мирового экономического кризиса на фоне нарастания угрозы пандемии произошли существенные сдвиги и в области учебной мотивации. В частности, вырос относительный рейтинг внутренних мотивов личности. Последние не всегда являются стабильными. При разработке стратегии и методик подготовки будущих ИТ-специалистов это необходимо учитывать.

Изучение феномена «Мотивация» с позиций теории динамических систем позволяет выявить его скрытые особенности и предложить новые механизмы и средства усиления. Ранее в наших исследованиях [5] на основе метода нечёткого когнитивного анализа выявлена корреляция между уровнем учебной мотивации, методикой и результатами обучения студентов. Как показывает накопленный педагогический опыт, внутренняя мотивация студентов может быть усилена путем целенаправленной работы профессорско-преподавательского состава (ППС) и на основе правильной расстановки акцентов в образовательной программе. Установлено также, что внешняя мотивация обучающихся изменяется под воздействием факторов различной природы, которые отражают актуальные запросы общества на специалистов конкретного профиля и в явном виде не связаны с учебной деятельностью. 


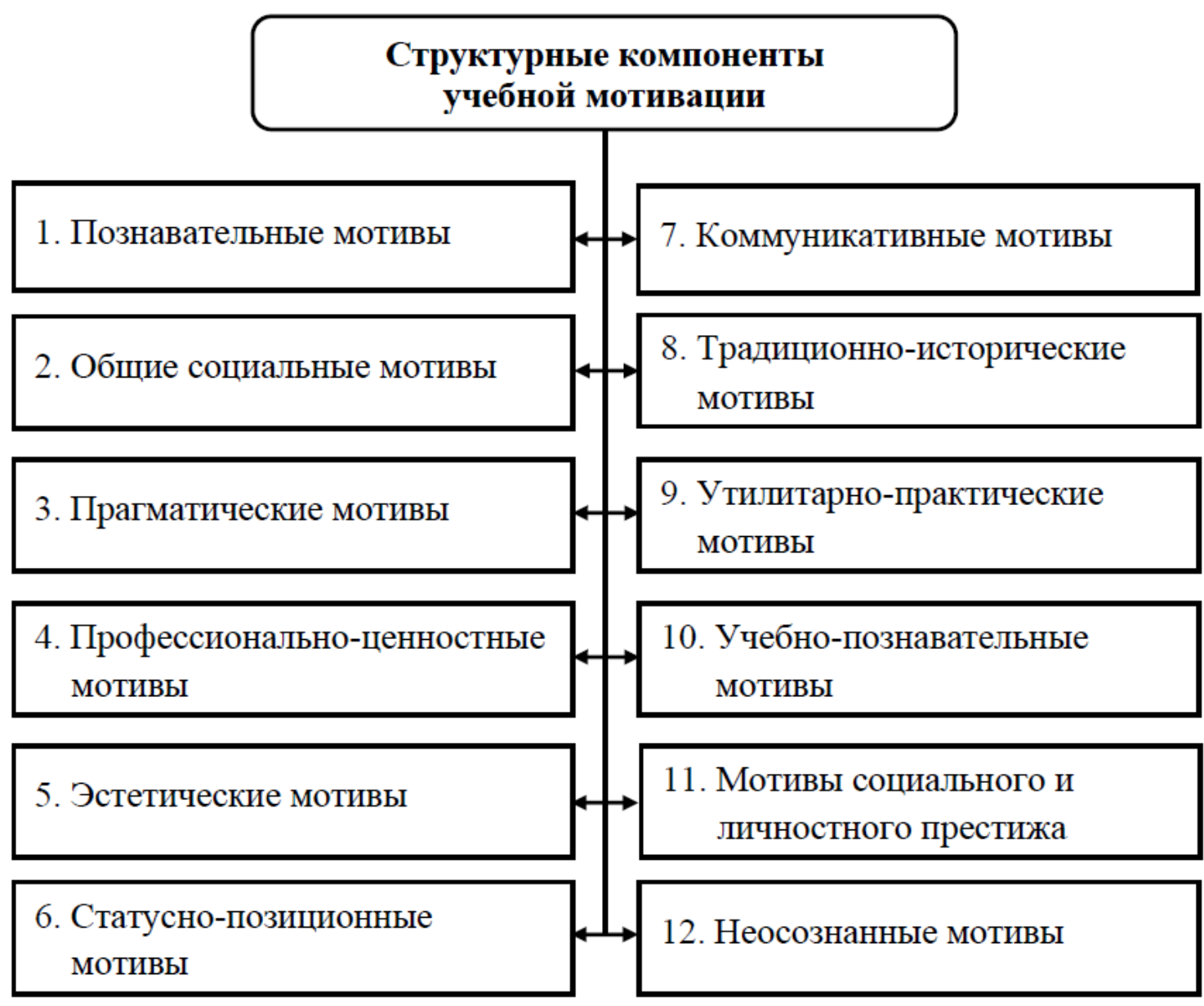

Рисунок 1. Основные компоненты учебной мотивациии

Анализ данных анкетирования студентов университета, обучающихся по направлениям подготовки 02.03.02 «Фундаментальная информатика и информационные технологии» и 09.03.03 «Прикладная информатика», позволил выявить группу доминирующих факторов, побуждающих студентов к активной учебной деятельности. Среди таких факторов выделим следующие:

- концептуальную модель будущей профессиональной деятельности, в которой через систему мировозренческих принципов и прагматическую позицию обучающегося интерпретируются индивидуальные цели обучения;

- активную жизненную позицию и стремление к самоутверждению;

- понимание своей роли в коллективе и осознание студентом личной значимости (в команде единомышленников) для успешной реализации идей ИТ-проекта;

- уверенность в собственных профессиональных знаниях, умениях и навыках;

- наличие одобрения и моральной поддержки от родственников и товарищей по учебной группе;

- $\quad$ традиции и имидж образовательной организации, квалификацию ППС;

- $\quad$ авторитет и личный пример ведущих преподавателей университета;

Среди современных образовательных технологий, обладающих большим дидактическим потенциалом, выделим метод проектного обучения [6]. Метод проектного обучения хорошо зарекомендовал себя в педагогической практике и отличается высокой гибкостью и универсальностью. Его использование в учебном процессе открывает дополнительные возможности для индивидуализации обучения и 
активизации познавательной активности студентов. Выделим ряд особенностей известного метода, которые легли в основу разработанной нами концепции активного проектного обучения:

- организация учебной деятельности студентов с опорой на общие требования нормативных документов, регламентирующих процесс разработки автоматизированных информационных систем и технологий в ведущих отечественных проектных организациях и фирмах;

- $\quad$ наличие апробированного материально-технического, методического, и информационного обеспечения учебного процесса;

- целенаправленная деятельность студентов в составе единой команды в интересах создания ИТ-проекта (или его составной части), имеющего новизну и очевидный общественно-значимый и/или коммерческий эффект;

- привлечение для автоматизированного решения проектных задач современных CASE-технологий и пакетов прикладных программ;

- систематический обмен опытом проектирования с коллективным обсуждением проблемных вопросов и экспертной оценкой промежуточных результатов разработки проекта;

- применение передового опыта и технологий проектирования информационных систем и, в частности, технологии прототипирования;

- апробация результатов проектирования путем подготовки студентами научных докладов и сообщений.

Анализ реального положения дел показал, что проблема учебной мотивации студентов для многих российских вузов сегодня является очень острой. Для наукоёмких специальностей, связанных с изучением теории и практики информатики, именно высокая мотивация к обучению выступает необходимым условием и одновременно катализатором интенсификации учебного процесса.

C учетом положений изложенной выше концепции активной проектной деятельности нами разработана методика выполнения студентом научноисследовательской работы (НИР) (см. рис.2) в соответствии с полученным индивидуальным заданием.

Для определённости отметим, что в 4-м семестре бакалавриата в качестве НИР предусматривается подготовка научного реферата. Тема для исследования (в рамках НИР) студентом выбирается самостоятельно из предложенного ведущим преподавателем списка. После выбора темы студент получает индивидуальное задание от преподавателя и поэтапно проводит исследования в точном соответствии с методикой выпускающей кафедры.

Поэтапно студент выполняет методические рекомендации, постепенно погружаясь в предметную область НИР, расширяет свой кругозор, формирует первичные умения и приобретает навыки научного исследования. Преподаватель ненавязчиво направляет студента и поощряет его активную самостоятельную работу. Как показал многолетней опыт педагогической работы, при соответствующей организации, качественном методическом и информационном обеспечении учебной практики, НИР выходит на технологический уровень. При этом у студентов по мере накопления личного опыта неизбежно усиливается мотивация к обучению. Такой эффект возрастает в процессе освоения студентом современных инструментальных программных средств и при появлении первых значимых научных достижений. Возникает механизм положительной обратной связи, который укрепляет познавательный интерес, способствует самовыражению и самоутверждению обучающегося и развивает индивидуальные способности: целеустремлённость, настойчивость, аккуратность, рассудительность, креативное мышление и другие. 


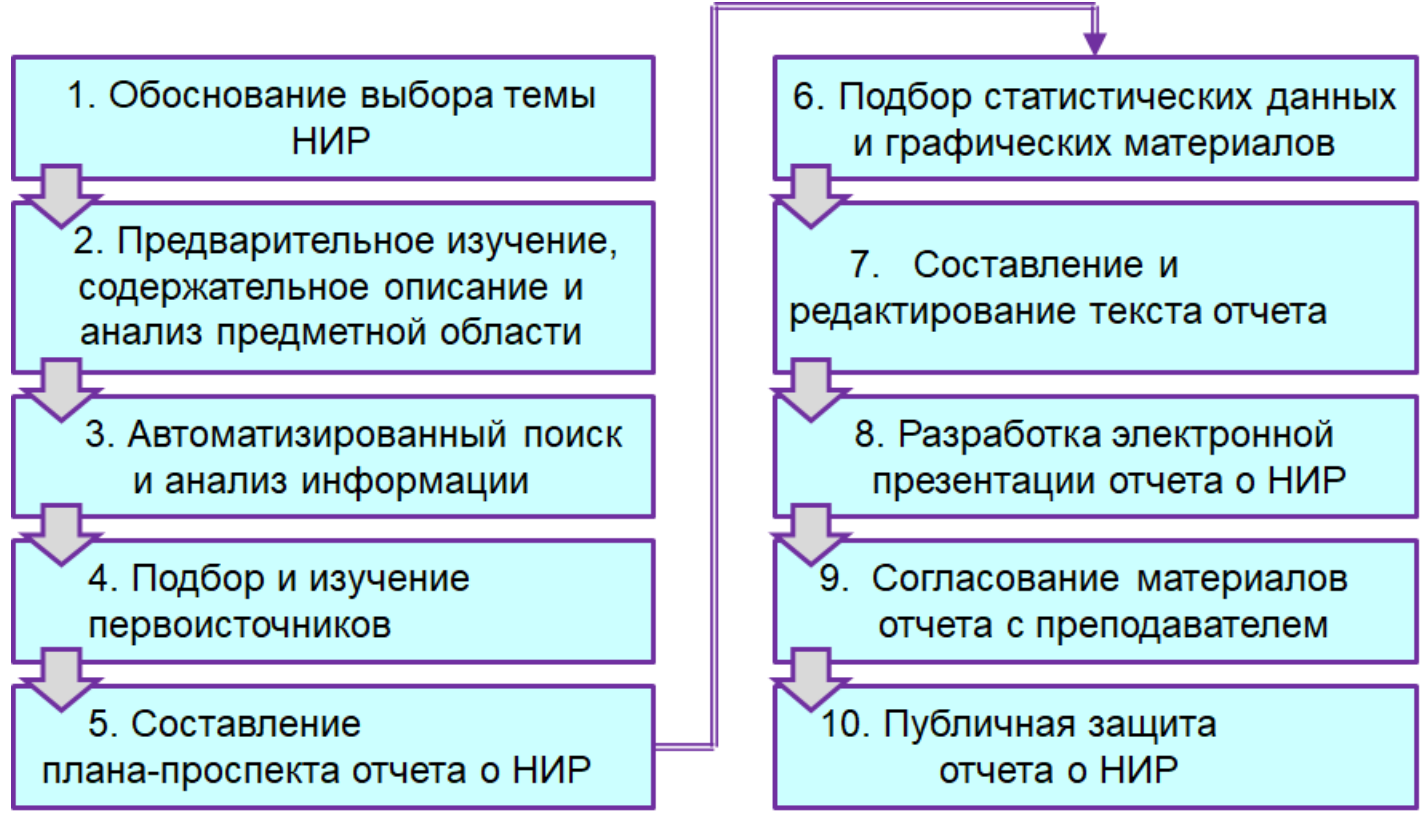

Рисунок 2. Методика выполнения НИР в процессе учебной практики

В ходе педагогических исследований установлено, что для поддержания мотивации обучающихся на достаточном для качественного обучения уровне необходим комплексный подход к обучению и воспитанию. Как показали наши исследования [6], комплексный подход к целенаправленному формированию ключевых мотивов обучающихся является наиболее адекватным ответом на тенденцию снижения качества инженерного образования. Ядро комплексного подхода, имеющего хорошо разработанную теоретико-методологическую базу, в нашем случае должны составлять следующие положения [7]:

- ознакомление студентов с основами рациональной организации творческого труда, методами научных исследований и способами представления результатов интеллектуальной деятельности;

- раскрытие панорамы направлений искусственного интеллекта, перспектив цифровизации экономики, результатов развития и конвергенции науки и критических технологий Российской Федерации;

- $\quad$ показ на конкретных примерах возможности и способы применения на практике профессиональных компетенций ИТ-специалиста;

- индивидуализация обучения, предполагающая выбор набора дидактических средств (форм обучения и воспитания) с учетом когнитивного стиля обучающегося;

- $\quad$ создание в учебной группе студентов атмосферы творчества и взаимной поддержки при сохранении определённого уровня состязательности;

- научно-методическая и информационная поддержка и одобрение познавательной активности, инициативы и самостоятельности студентов при выполнении НИР;

- плановое привлечение студентов к популяризации научных и технических достижений российских ученых, конструкторов, инженеров;

- $\quad$ развитие существующей балльно-рейтинговой системы оценки знаний и творческих достижений студентов с учётом профиля обучения и особенностей (структуры и содержания) НИР. 


\section{Выводы:}

1. Устойчивая учебная мотивация студента - одно из необходимых условий успешного освоения им содержания основной образовательной программы по подготовке ИТ-специалистов.

2. Для поддержания высокой учебной мотивации студентов - будущих ИТ-специалистов - предложен комплексный подход, предусматривающий выделение и целенаправленное воздействие педагогическими средствами на ключевые мотивы, побуждающие студентов к активной учебной и творческой деятельности.

3. Эффективность разработанных рекомендаций по стабилизации учеб-ной мотивации обучающихся подтверждена при осуществлении научноисследовательской практики студентов, обучающихся на втором курсе по направлению 02.03.02 «Фундаментальная информатика и информационные технологии».

$$
* * *
$$

1. Занюк С.С. Психология мотивации. Теория и практика мотивирования. Мотивационный тренинг. Киев: Эльга-Н: Ника-Центр. 2001. 351 с.

2. Сатаева Е.И. Исследование мотивации достижения в работах отечественных ученых / Инновации в системе непрерывного профессионального образования: Сборник статей по материалам Международной научно-практической конференции преподавателей вузов, ученых и специалистов (22.03.2020 г.). - Н. Новгород: ВГИПУ, 2010. - С. 292-296.

3. Стародубцева В.К. Мотивация студентов к обучению // Современные проблемы науки и образования. - 2014. - № 6.; URL:http://science-education.ru/ru/article/view?id=15617 (дата обращения: 09.04.2021).

4. Гордеева Т.О. Мотивация: новые подходы, диагностика, практические рекомендации // Сибирский психологический журнал. 2016. № 62. С. 38-53.

5. Надеждин Е.Н. Когнитивный стиль и мотивация как ключевые концепты семантической модели системы подготовки будущего ИТ-специалиста /Роль науки и образования в модернизации и реформировании современного общества: Сборник статей Международной научно-практической конференции (17.10.2020 г., г. Казань). - Уфа: OMEGA SCIENCE, 2020. С. 171-175.

6. Надеждин Е.Н. Метод проектов в системе обучения магистрантов по направлению подготовки «Прикладная информатика»/ В сб.: Образование и педагогика: теория и практика. Сборник материалов Всероссийской научно-практической конференции. БУ ЧР ДПО «Чувашский республиканский институт образования» Министерства образования и молодежной политики Чувашской Республики. Чебоксары, 2020. С. 45-48.

7. Надеждин Е.Н. Особенности и пути усиления учебной мотивации студентов при изучении наукоёмких дисциплин // Актуальные проблемы методики обучения информатике и математике в современной школе: материалы Международной научно-практической интернет-конференции, г. Москва, 22-26 апреля 2019 г. / под ред. Л.Л. Босовой, Д.И. Павлова; Московский педагогический государственный университет. Кафедра теории и методики обучения математике и информатике [Электронное издание]. - Москва: МПГУ, 2018. С. 604-702.

\section{Петренко А.А. \\ О необходимости формирования компетенций руководителей образовательных организаций в области командообразования}

Рязанский государственньй университет имени С.А. Есенина (Россия, Рязань)

doi: 10.18411/lj-05-2021-244

\section{Аннотация}

В статье обосновывается потребность развития способностей руководителей образовательных систем к управлению педагогическими коллективами на принципах командообразования.

Ключевые слова: команда, управление, образовательная организация, управленческая команда, компетенции руководителей образовательных организаций. 